\title{
Prevalence of Iron Deficiency Anemia among Adolescent Girls in the City of Saravan
}

\author{
Omid Sabet Ghadam ${ }^{1}$, Mohammad Fararouei ${ }^{2}$, Mansour Shahraki ${ }^{3}$ and Zahra Sohrabi ${ }^{1, *}$ \\ ${ }^{1}$ Department of Community Nutrition, School of Nutrition and Food Sciences, Shiraz University of Medical \\ Sciences, Shiraz, Iran \\ ${ }^{2}$ Department of Epidemiology, School of Health, Shiraz University of Medical Sciences, Shiraz, Iran \\ ${ }^{3}$ Department of Nutrition \& Food Technology, Medical Faculty, Zahedan University of Medical Sciences, \\ Zahedan, Iran
}

\begin{abstract}
Background and Objective: Iron deficiency anemia (IDA) is the most common type of micronutrient deficiency in the world. Numerous reports indicated that adolescence is a period which has an increased risk of development of IDA. Given the importance of IDA and lack of studies in Saravan, a city of Iran, this study was performed to assess the prevalence of IDA among adolescent girls.

Methods: In this cross-sectional study, 460 high-school girls were randomly selected. Demographic data was collected using a questionnaire. Knowledge, attitude and practice of participants with regard to iron deficiency anemia was measured at the beginning of the interview. Accordingly, five cc of blood sample was drawn from each student to determine the prevalence of anemia, which was defined by a hemoglobin level lower than $12 \mathrm{mg} / \mathrm{dL}$. The level of ferritin was analyzed to confirm the IDA for students diagnosed with anemia. Ferritin level lower than $12 \mu \mathrm{g} / \mathrm{dl}$ was considered as IDA. Data was analyzed using SPSS software version 22

Results: Prevalence of anemia and IDA was $24 \%(n=111)$ and $12.6 \%(n=58)$, respectively. Results showed that $37 \%$ of students had good knowledge, $45.5 \%$ good attitude, and $6.7 \%$ had good practice. Also, there was no significant association between IDA and socio-economic status including parental education, job, and household income $(P>0.05)$.

Conclusion: The findings of this study showed that the prevalence of IDA was moderate in Saravan city. Given the importance of IDA and its complications, further studies are needed, especially in high risk populations for IDA such as children.
\end{abstract}

Keywords: Iron deficiency anemia, adolescent girls, Iron stores.

\section{INTRODUCTION}

Iron deficiency is the most common type of nutritional deficiency in the world which could affect physical, mental and individual health [1]. Iron deficiency anemia (IDA) occurs when iron reserves are reduced and there is not sufficient iron for normal synthesis of hemoglobin [2]. According to the World Health Organization (WHO), about two billion people suffer from anemia worldwide, most of which is due to iron deficiency [3]. In a study by Dalman et al. the prevalence of anemia in adolescent girls (13-15 years) and young women in USA were $5.9 \%$ and $5.8 \%$, respectively [4]. In Iran, the prevalence of anemia and IDA among high-school girls in city of Yazd was reported $13.5 \%$ and $9.3 \%$, respectively [5], and also, $9.5 \%$ and $4.5 \%$, respectively, in city of Semnan [6]. A study conducted among high school girls in East Azerbaijan, a province in Iran, reported the prevalence

*Address correspondence to this author at the Department of community nutrition, School of Nutrition and Food Sciences, Shiraz University of Medical Sciences, Shiraz, Iran; Tel: 00987137251002; Fax: 00987137257288

E-mail: sohrabi@sums.ac.ir of iron deficiency, anemia, and IDA, $60.7 \%, 12.6 \%$, and $11.5 \%$, respectively [7]. A study in city of Birjand reported the prevalence of iron deficiency and IDA in middle school girls $24 \%$ and $1.8 \%$, respectively [8].

Pre-school children, adolescents, pregnant women, and religious minorities are among the high- risk groups for anemia [9]. Although IDA is a multifactorial complication, it generally occurs as a result of increased need of iron, inadequate intake, disturbed absorption and transportation, and physiological excretion of iron through menstruation, or acute and chronic bleeding [5]. Other causes of anemia include parasitic infection with hookworms, acute and chronic infections such as malaria, tuberculosis, AIDS, nutritional deficiencies such as low intakes of vitamin $A$, B12, folic acid, riboflavin, copper and also, drug use, and some type of cancers [10]. IDA is associated with clinical symptoms such as pale conjunctiva, shortness of breath, dizziness, and weakness [11]. IDA in pregnancy is associated with several outcomes such as increased risk of maternal mortality, preterm birth, low birth weight infants, and infants with low iron stores. Also, in children, it is associated with impaired

(C) 2020 SET Publisher 
cognitive development, poor learning capacity, and academic performance [12-14].

The prevalence of anemia among adolescents in developing and developed countries are reported $27 \%$ and $6 \%$, respectively [15]. Adolescent girls are more likely to suffer from the depletion of iron stores due to accelerated growth, nutritional deficiency, weight-loss diets, and menstrual bleeding $[5,16]$. Also, it can disrupt the learning capacity, reduce educational achievement, working capacity, and physical strength, and increases the risk of infections [12]. The studies also showed that the prevalence of IDA in girls is more than ten times higher than boys [17]. Therefore, assessment of IDA in adolescent girls who are future mothers is necessary.

Results of previous reports in different cities of Iran are not generalizable for the city of Saravan, and due to socioeconomic differences and its special geographical location near to Pakistan international border and lack of information about anemia in this population, this study aimed to determine the prevalence of IDA among adolescent girls and to determine the level of knowledge, attitude, and practice in this population in the city of Saravan.

\section{MATERIALS AND METHODS}

This cross-sectional study was performed in 2018 among adolescent girls aged from 10 to 19 who met the defined inclusion criteria. The purpose of study was explained to the parents and written informed consent was obtained if they were willing to let their children participate in this project and the study protocol was reviewed and approved by the ethics committee of Shiraz University of Medical Sciences, Iran. General characteristics of students including parental education, occupation, monthly income, family size, and birth order were completed using a researcher-designed questionnaire. The students were included if they: 1) aged 10-19 years, 2) had no history of cardiovascular or other chronic diseases, 3) experienced menstruation for at least one year, 4) no history of severe menstrual bleeding, 5) no history of severe infection or fracture and 6) not using iron supplements and other vitamin/mineral supplements. Exclusion criteria were: 1) unwillingness to cooperate, 2) having diseases that require treatment.

A total of 460 high-school students were randomly selected for assessment of IDA. Knowledge, attitude and practice of the participants was assessed by a selfadministered questionnaire. Accordingly, knowledge was measured by 21 questions, attitude measured by 18 questions based on a Likert scale: Strongly agree, agree, disagree, and strongly disagree. Also, practice was measured by 11 questions based on three choices: often, sometimes, never.

\section{Blood Sampling}

To define the status of anemia, 5 cc of blood sample was obtained from each student to determine the status of anemia. Those with hemoglobin less than $12 \mathrm{mg} / \mathrm{dL}$ were defined as anemic. Among students with anemia, the level of ferritin was analyzed to confirm IDA, which was defined as a ferritin level $<12$ $\mu \mathrm{g} / \mathrm{dl}$.

\section{Sample Size}

The sample size was calculated to be 460 subjects, based on the reported prevalence of IDA $(5 \%)$ in a study by Abedini et al. [18].

\section{Measurement of Height, Weight, Waist Circumference, and Body Mass Index}

Weight was assessed using the SECA scale with an accuracy of $100 \mathrm{~g}$, with subjects having minimal clothes and no shoes on. Waist circumference (WC) was measured using a non-elastic tape with accuracy of 0.1 $\mathrm{cm}$ at the point of iliac crest. Height was measured in the standing position and without shoes using the stadiometer with an accuracy of $0.5 \mathrm{~cm}$. Also, body mass index (BMI) was calculated by dividing weight to square of height.

\section{Laboratory Tests}

After selecting the students and obtaining written informed consent, $5 \mathrm{cc}$ of blood sample was initially collected by a laboratory staff to determine the levels of haemoglobin and ferritin. Accordingly, the blood sample was poured into two separate containers to measure hemoglobin (one cc in EDTA- containing glass tube) and ferritin in a hemolysis tube, which was kept at minus $70^{\circ} \mathrm{C}$ until laboratory analysis. The laboratory tests used to assess the prevalence of IDA was serum hemoglobin and ferritin. Students with serum hemoglobin lower than $12 \mathrm{~g} / \mathrm{dl}$ were considered to have anemia and those with ferritin level lower than $12 \mathrm{~g} / \mathrm{dl}$ were diagnosed with IDA [19].

\section{Statistical Analysis}

Data was analyzed using SPSS software version 22 by Chi-Square and Fisher tests, and a P-value less than 0.05 was considered as statistically significant. 


\section{RESULTS}

This study was conducted on 460 adolescent girls. The prevalence of anemia and IDA were $24 \%(n=111)$ and $12.5 \%(\mathrm{n}=58)$, respectively. The mean (and standard deviation) levels of serum hemoglobin, hematocrit, $\mathrm{MCV}, \mathrm{MCH}$, and $\mathrm{MCHC}$ were 12.85 (1.85), 37.25 (4.57), 81.90 (36.62), 27.95 (5.34), and 34.50 (2.18), respectively (Table 1 ).

Table 1: Mean Values of Study Variables among Adolescent Girls in the City of Saravan

\begin{tabular}{|c|c|c|c|}
\hline Variables & Mean & Standard deviation & P-value $^{*}$ \\
\hline \hline $\mathrm{WC}(\mathrm{cm})$ & 69.252 & 9.44836 & 0.687 \\
\hline $\mathrm{BMl}\left(\mathrm{kg} / \mathrm{m}^{2}\right)$ & 20.957 & 4.68180 & 0.101 \\
\hline Weight(kg) & 47.420 & 11.08043 & 0.256 \\
\hline Height $(\mathrm{cm})$ & 150.66 & 9.71782 & 0.771 \\
\hline Hemoglobin(g/dl) & 12.855 & 1.61378 & \\
\hline $\mathrm{HCT}(\%)$ & 37.255 & 4.57459 & \\
\hline $\mathrm{MCV}(\mathrm{fL})$ & 81.906 & 36.62561 & \\
\hline $\mathrm{MCH}(\mathrm{pg})$ & 27.953 & 5.34116 & \\
\hline $\mathrm{MCHC}(\mathrm{g} / \mathrm{dl})$ & 34.550 & 2.18384 & \\
\hline
\end{tabular}

WC: Waist Circumference; BMI: Body mass index; HCT: Hematocrit; MCV: mean corpuscular volumes; MCH: Mean corpuscular hemoglobin; MCHC: Mean corpuscular hemoglobin concentration.

*The significant level between the quantitative variables with the prevalence of IDA.

Table 2: Demographic Variables and their Associations with Iron-Deficiency Anemia among Adolescent Girls in the City of Saravan

\begin{tabular}{|c|c|c|c|c|}
\hline \multicolumn{2}{|c|}{ Demographic variables } & Frequency & Percentage & $P$ value \\
\hline \multirow{3}{*}{ Family size } & $1-2$ & 10 & 2.2 & \multirow{3}{*}{0.656} \\
\hline & 3 & 21 & 4.5 & \\
\hline & 4 and higher & 432 & 93.3 & \\
\hline \multirow{4}{*}{ Father's occupation } & Employee & 107 & 23.1 & \multirow{4}{*}{0.229} \\
\hline & Worker & 64 & 13.8 & \\
\hline & Self-employed & 214 & 46.2 & \\
\hline & Unemployed & 78 & 16.8 & \\
\hline \multirow{3}{*}{ Mother's occupation } & Housewife & 429 & 92.7 & \multirow{3}{*}{0.666} \\
\hline & Employee & 27 & 5.8 & \\
\hline & Retired & 7 & 1.5 & \\
\hline \multirow{3}{*}{ Father's education } & Illiterate & 64 & 13.8 & \multirow{3}{*}{0.393} \\
\hline & Primary and middle school & 197 & 42.5 & \\
\hline & Diploma and higher & 202 & 43.7 & \\
\hline \multirow{3}{*}{ Mother's education } & Illiterate & 128 & 27.6 & \multirow{3}{*}{0.586} \\
\hline & Primary and middle school & 245 & 52.9 & \\
\hline & Diploma and higher & 90 & 19.4 & \\
\hline \multirow{3}{*}{ Household income } & Sufficient & 210 & 45.4 & \multirow{3}{*}{0.979} \\
\hline & Relatively sufficient & 218 & 47.1 & \\
\hline & Insufficient & 35 & 7.6 & \\
\hline \multirow{3}{*}{ Student's GPA in last year } & 10 to 16 & 40 & 8.6 & \multirow{3}{*}{0.107} \\
\hline & 16 to 18 & 198 & 42.8 & \\
\hline & 18 to 20 & 225 & 48.6 & \\
\hline \multirow{3}{*}{ Birth order } & First & 133 & 28.7 & \multirow{3}{*}{0.693} \\
\hline & Second & 109 & 23.5 & \\
\hline & Third and higher & 221 & 47.7 & \\
\hline
\end{tabular}

GPA: Grade Point Average.

${ }^{1}$ The significant level between the demographic variables with prevalence of IDA. 
Table 3: Knowledge, Attitude and Practice of Students about Iron Deficiency Anemia

\begin{tabular}{|c|c|c|c|c|}
\hline & Poor & Moderate & Good & P-value $^{*}$ \\
\hline \hline Knowledge & 11.2 & 51.6 & 37.1 & 0.708 \\
\hline Attitude & 12.3 & 42.3 & 45.4 & .0733 \\
\hline Practice & 44.9 & 47.5 & 7.6 & 0.186 \\
\hline
\end{tabular}

*The significant level between knowledge status, attitude and practice with the prevalence of IDA.

In this study, $47.1 \%$ of the respondents had relatively sufficient household income. Also, the occupation of fathers of $46.2 \%$ of study subjects was self-employed and $43.7 \%$ of fathers were high school graduated or higher. The majority of mothers $(92.7 \%)$ were housewives and $59.9 \%$ had primary/middle school education (Table 2).

Table 3 shows the knowledge, attitude and practice of students regarding IDA. Results show that $11.2 \%$ had poor knowledge, $51.6 \%$ had moderate and $37.1 \%$ had good knowledge. Also, $12.3 \%$ had poor attitude, $42.3 \%$ had moderate attitude and $45.4 \%$ had good attitude. Moreover, $44.9 \%$ had poor practice, $47.5 \%$ had moderate practice and $7.6 \%$ had good practice.

In this study, parental occupation, education, family size, household income, birth order, and grade point average (GPA) of students had no statistically significant association with anemia and IDA. Also, there was no significant association between weight, height, WC, and BMI with the prevalence of anemia and IDA. In this study, there was no statistically significant association between the state of knowledge, attitude and practice with iron deficiency anemia.

\section{DISCUSSION}

In the present study, the prevalence of anemia and IDA is $24 \%$ and $12.6 \%$, respectively. While the prevalence of IDA among students and adolescents in the developing countries is reported between $29.2 \%$ to $79.6 \%$ [20]. The prevalence of anemia and IDA in adolescent girls was reported $27 \%$ and $32 \%$ in Bangladesh and $39.9 \%$ and $11.6 \%$ in Egypt, respectively $[21,22]$. In a study conducted in Canada, the prevalence of anemia was reported $14 \%$, which was almost in agreement with the findings of the present study [23].

In a study by Dalman et al. in 2003, the prevalence of anemia among adolescents in USA was $5.9 \%$ [4]. In Iran, the prevalence of anemia and IDA among highschool girls were reported $13.5 \%$ and $9.53 \%$, respectively, in city of Yazd [5] and also, $9.5 \%$ and 4.5
$\%$, respectively, in city of Semnan [6]. Also, another study in city of Kermanshah had reported the prevalence of anemia and IDA $23.7 \%$ and $12.2 \%$, respectively [20], which is almost similar to the prevalence rate in the present study. The reason for differences in the prevalence of IDA between studies is partly due to geographical differences and also might be due to the differences in sampling season and climate conditions as well as the intake of iron supplements, and different cut-off-points of hemoglobin for definition of IDA and genetic conditions.

In this study, there was no relationship between anemia and IDA with socioeconomic factors such as parental education level, occupation, and household income. While in a study conducted in Malaysia, the prevalence of anemia and IDA were significantly higher in students who had low-education (less than 6 years of education), low-income, and unemployed parents [24]. However, in another study in Saudi Arabia, the authors showed that there was no relationship between parental education and prevalence of anemia and IDA [25]. Also, another study in the city of Birjand in 2006, found no association between parental education and IDA [8]. The differences in the results of studies might be due to the differences in sample size or characteristics of the study population.

In this study, there was no relationship between the prevalence of anemia and IDA with GPA of students, which is similar to the findings of a study conducted in Birjand in 2006 [8]. Also, a study conducted in city of Kermanshah reported similar results, however, they found a significant correlation between serum ferritin levels and students' academic achievement [26]. In contrast, a study conducted in Saudi Arabia in 2009 reported a statistically significant association between students' GPA and IDA [25].

In the present study, no significant association was found between weight, height, BMI, and WC with prevalence of IDA, which is in agreement with results of a study conducted in Korea in 2014 [27]. Also, in a study conducted in city of Kermanshah, students' BMI was not associated with the prevalence of IDA [26]. 
Although, in another study in city of Kerman, there was a significant association between BMl with serum hemoglobin and hematocrit [28].

Several factors have been proposed to explain the association between obesity and IDA including genetic condition, physical inactivity which leads to the reduced iron circulation, impaired intestinal absorption, inadequate intake of dietary iron and increased need for iron. Therefore, the low levels of serum iron in obese individuals might be due to the combination of both nutritional and functional factors [29]. Also, studies have shown that the hematological parameters used for diagnosis of IDA were associated with body fat percentage but not $\mathrm{BMI}$, which could reflect the limitations of BMI in definition of obesity [30].

In this study, there was no statistically significant association between knowledge status, attitude and practice with iron deficiency anemia. A study conducted in 2009 in Lorestan also concluded that there was no significant association between hemoglobin and ferritin and students' knowledge scores [31]. A study conducted in Pakistan in 2017 concluded that there was no statistically significant association between hemoglobin level and students' knowledge score, whereas there was a significant statistical association between hemoglobin level and attitude score and performance [32]. Also, a study conducted in India in 2015 concluded that there was no statistically significant association between level of knowledge and attitude and level of hemoglobin [33].

One of the limitations of this study was the age range of the study subjects. Since other age groups such as children are also susceptible to IDA, including them into the study have provided a better assessment of IDA in the city of Saravan. Since there has been no study to date on the prevalence of IDA in city of Saravan, conducting such study in large sample size is the main strength of this study, because Saravan is a special city with a specific geographical location as it is near to the international border of Pakistan and might share some features including dietary habits and medical services with that country which is different from Iran

\section{CONCLUSION}

IDA is a common health problem worldwide, but its prevalence varies between geographic regions depending on environmental factors and nutritional patterns. In the present study, the prevalence of IDA was $12.6 \%$ in Saravan city, south of Iran, which is classified as the mild prevalence rate according to the WHO criteria [34]. Given the differences in the prevalence of IDA and also because of its health, social, and economic consequences, it is recommended that further studies be conducted in other vulnerable groups and other places with different socioeconomic and geographical features. Moreover, with regard to the prevalence of IDA in adolescent girls, treatment interventions or preventive programs are needed to control anemia in this group after defining the high risk regions. Moreover, further studies in various geographilal locations and different ages are warranted to better elucidate the high risk populations for anemia and to design nutritional interventions and programs in the susceptible regions or groups for the sake of management of anemia. On the other hand, after defining the high risk populations, interventional studies are needed to eradicate anemia in these groups to enhance the productivity and health in different communities and to decrease health costs related to anemia.

\section{REFERENCES}

[1] Shahalvand F, Ghazanfari Z, Gholami Parizad E, Pournajaf A $\mathrm{H}$, Ranjbar E. Assessing Knowledge Attitude and Practice of Ilam Girl High School Students Towards Iron Deficiency Anemia 2013. sjimu 2015; 23 (4): 209-216.

[2] Conrad ME, Umbreit JN. Iron absorption and transport-an update. American journal of hematology 2000; 64(4): 287-98. https://doi.org/10.1002/1096-8652(200008)64:4<287::AIDAJH9>3.0.CO;2-L

[3] World health Organization $\mathrm{WH}$. Turning the tide of malnutrition: responding to the challenge of the 21st century. Geneva: World Health Organization; 2000.

[4] Kınık E. Derman O, Öksüz-Kanbur N, Yenicesu I, Iron deficiency anemia in a group of Turkish adolescents: Frequency and contributing factors De Gruyter; 2005. https://doi.org/10.1515/IJAMH.2005.17.2.179

[5] Mozaffari-Khosravi $H$, Noori Shadkam M, Naghiaee $Y$. prevalence of Iron deficiency and Iron deficiency anemia in high-school girl students of yazd. SSU_Journals 2009; 17(3): 135-41.

https://doi.org/10.1007/s12011-009-8480-0

[6] Fakhri Ma, Ahadi F. Prevalence Of Iron Deficiency Anemia In High School Girls In Semnan City 2005.

[7] Pourghassem B, Kimiagar G, Abolfathi A, Vallaii $N$, Ghaffarpour M. Prevalence of iron deficiency, anaemia, and iron-deficiency anaemia in high-school students in Jolfa, East Azerbaijan. Food and Nutrition Bulletin 2000; 21(3): 301-4. https://doi.org/10.1177/156482650002100309

[8] Fesharakiniya A, Sharifzadeh G, Sadrzadeh, M, Segalahgi $\mathrm{H}$. Prevalence of iron deficiency and its related anemia in junior school students in Birjand. J Birjand Univ Med Sci 2007; 14 (3): 9-15.

[9] Premalatha T, Valarmathi S, Srijayanth P, Sundar J, Kalpana S. Prevalence of anemia and its associated factors among adolescent school girls in Chennai, Tamil Nadu, India. Epidemiology 2012; 2(118): 1165-2161.

[10] De Benoist 10-B, Cogswell M, Egli I, McLean E. Worldwide prevalence of anaemia 1993-2005; WHO Global Database of anaemia 2008. 
[11] Chen M-H, Su T-P, Chen Y-S, Hsu J-W, Huang K-L, Chang $\mathrm{W}-\mathrm{H}$, et al. Association between psychiatric disorders and iron deficiency anemia among children and adolescents: a nationwide population-based study. BMC psychiatry 2013; 13(1): 161

https://doi.org/10.1186/1471-244X-13-161

[12] Olude O. Impact of nutrition education and counseling on anemia prevalence and iron status in women of reproductive age: a systematic review: Doctoral dissertation. Emory University: 2005.

[13] Pasricha S-R, Biggs B-A, Prashanth $N$, Sudarshan $H$, Moodie R, Black J, et al. Factors influencing receipt of iron supplementation by young children and their mothers in rural India: local and national cross-sectional studies. BMC public health $2011 ; 11(1): 617$ https://doi.org/10.1186/1471-2458-11-617

[14] Yalçın SS, Tezel B, Yurdakök K, Pekcan G, Özbaş S, Köksal $E$, et al. A community-based iron supplementation program,"Iron-Like Turkey", and the following prevalence of anemia among infants aged 12-23 months. Turk J Pediatr 2013; 55: 16-28.

[15] Baker Jr WF. Iron deficiency in pregnancy, obstetrics, and gynecology. Hematology/oncology clinics of North America 2000; 14(5): 1061-77. https://doi.org/10.1016/S0889-8588(05)70171-4

[16] Khazaee T, Zardast M, SADAT JS. Prevalence of Iron deficiency anemia in Birjand high school students 2003.

[17] Schaaf D, Scragg R, Metcalf P, Grant C, Buchanan J. Prevalence of iron deficiency in Auckland high school students 2000.

[18] Abedini S, Shahi A, Abedini S, Aghamolaei T. Prevalence of anemia and Iron deficiency anemia in high school girls of Bandar Abbas in 2013. Journal of Preventive Medicine 2016; 3(1): 43-37.

[19] Akramipour R, Rezaei M, Rahimi Z. Prevalence of iron deficiency anemia among adolescent schoolgirls from Kermanshah, Western Iran. Hematology 2008; 13(6): 352-5. https://doi.org/10.1179/102453308X343383

[20] Morón C, Viteri FE. Update on common indicators of nutritional status: food access, food consumption, and biochemical measures of iron and anemia. Nutrition reviews 2009; 67(suppl 1): S31-S5. https://doi.org/10.1111/j.1753-4887.2009.00156.x

[21] Islam M, Kabir I, Fuchs GJ, Ahmed F, Khan M. Anaemia and iron deficiency among adolescent schoolgirls in peri-urban Bangladesh. European journal of clinical nutrition 2000; 54(9): 678.

https://doi.org/10.1038/sj.ejcn.1601073

[22] Mousa SMO, Saleh SM, Higazi AMM, Ali HAA. Iron deficiency and iron deficiency anemia in adolescent girls in rural upper Egypt. International Blood Research \& Reviews 2016: 1-6.

https://doi.org/10.9734/IBRR/2016/25826
[23] Alaofe H, Zee J, O'Brien HT. Dietary iron and iron deficiency anemia among adolescent girls from Benin. Revue d'epidemiologie et de sante publique 2007; 55 . https://doi.org/10.1016/i.respe.2007.01.030

[24] Ngui R, Lim YAL, Kin LC, Chuen CS, Jaffar S. Association between anaemia, iron deficiency anaemia, neglected parasitic infections and socioeconomic factors in rural children of West Malaysia. PLoS neglected tropical diseases 2012; 6(3): e1550. https://doi.org/10.1371/journal.pntd.0001550

[25] Abalkhail B, Shawky S. Prevalence of daily breakfast intake iron deficiency anaemia and awareness of being anaemic among Saudi school students. International journal of food sciences and nutrition 2002; 53(6): 519-28. https://doi.org/10.1080/09637480220164370

[26] Pasdar Y, Heydarpour F, Darbandi M, Niazi P, Izadi N. Anemia, Iron Deficiency And Affecting Factors On It In Between Girls'students Of Kermanshah University Of Medical Science 2015

[27] Kim J, Shin S, Han K, Lee KC, Kim J, Choi YS, et al. Relationship between socioeconomic status and anemia prevalence in adolescent girls based on the fourth and fifth Korea National Health and Nutrition Examination Surveys. European journal of clinical nutrition 2014; 68(2): 253. https://doi.org/10.1038/ejen.2013.241

[28] Amirkhizi F, Siassi F, Djalali M, Minaie S. Assessment of body mass index and its relationship with iron status indices among women in rural areas of Kerman province, Iran. koomesh 2007; 9 (1): 41-46

[29] Haidari F, Haghighi-Zade M, Kayedani G, Birgani N K. Evaluation of the relationship between iron status with obesity and obesity-induced inflammation in female students. Tehran Univ Med J 2018; 76 (2): 129-134.

[30] Tabatabaei F, Sharif M, Kheirkhah D, Madani M. Iron profile in obese compared to normal children. Feyz Journal of Kashan University of Medical Sciences 2016; 20

[31] Falahi E, Rashidi M, Ebrahimzadeh F, Karbasi S, Shokrollahi $\mathrm{N}$. Effect of nutritional education on iron-deficiency anemia in high schools girls. J Shahrekord Univ Med Sci 2010; 12 (1): 37-45(1).

[32] Shahzad S, Islam K, Azhar S, Fiza S, Ahmed W, Murtaza Z. Impact of Knowledge, Attitude and Practice on Iron Deficiency Anaemia Status Among Females of Reproductive Age Group (20-21-year-old) Studying in Government Home Economics College Lahore, Pakistan. Int Arch BioMed Clin Res.

[33] Jose S, Antony S.C, Issac B.R. Impact of knowledge, Attitude and Practice on anemia status among women in coastal Kochi, Kerala. Int. J. of Multidisciplinary and Current Research 2016; 4: available at http: //ijmcr.com

[34] Arab M, Abbasszadeh A, Abazary F, Nikian Y. Prevalence of Anemia in 15-45 Year old Women Referring to the Health Centers of Bam, 2002. Journal of Rafsanjan University of Medical Sciences 2004; 3(3): 193-8.

Received on 07-01-2020

Accepted on 04-02-2020

Published on 12-03-2020

\section{DOI: https://doi.org/10.29169/1927-5951.2020.10.02.4}

(C) 2020 Sabet Ghadam et al.; Licensee SET Publisher.

This is an open access article licensed under the terms of the Creative Commons Attribution Non-Commercial License (http://creativecommons.org/licenses/by-nc/3.0/) which permits unrestricted, non-commercial use, distribution and reproduction in any medium, provided the work is properly cited. 